\title{
From Disability to Usability in Online Instruction
}

\author{
Susan David deMaine ${ }^{\star \star}$
}

This article is a primer on the work needed to ensure accessibility in online instruction. It discusses different disabilities, reviews relevant laws and standards, and explores the relationship between accessibility and the principles of universal design. The article introduces a number of best practices for creating accessibility in online instruction.

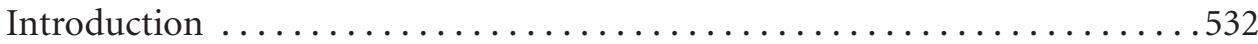

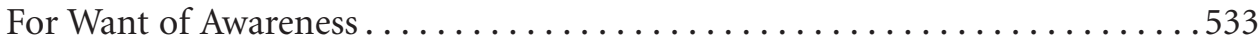

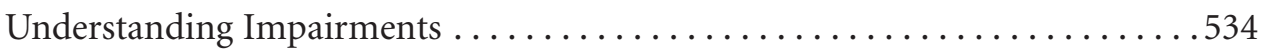

Visual Impairments . . . . . . . . . . . . . . . . . . . . . . . . 534

Hearing Impairments. . . . . . . . . . . . . . . . . . . . 536

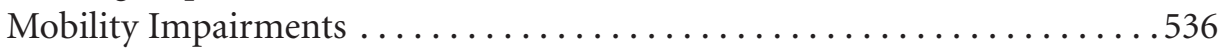

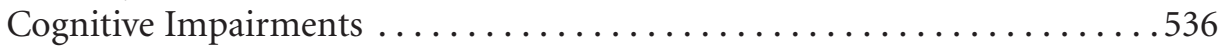

Nonnative Language Speakers. . . . . . . . . . . . . . . . . . . . . . 537

Accessibility Laws and Standards. . . . . . . . . . . . . . . . . . . 537

Section 504 of the Rehabilitation Act of $1973 \ldots \ldots \ldots \ldots \ldots \ldots \ldots \ldots \ldots . \ldots \ldots 7$

1998 Amendments to the Rehabilitation Act. . . . . . . . . . . . . . . 538

Americans with Disabilities Act . . . . . . . . . . . . . . . . . . . . 539

2008 Amendments to the ADA . . . . . . . . . . . . . . . . . . . 540

Twenty-first Century Communications and Video Accessibility

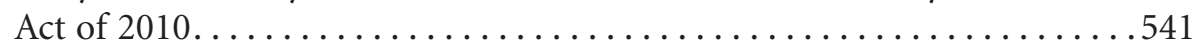

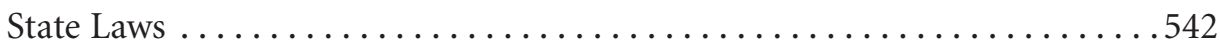

Industry Standards: Quality Matters, WCAG 2.0, Section $508 \ldots \ldots \ldots \ldots . . . .543$

Universal Design . . . . . . . . . . . . . . . . . . . . . 546

* C Susan David deMaine, 2014. This is a revised version of the winning entry in the New Member Division of the 2014 AALL/LexisNexis Call for Papers Competition. I would like to express my gratitude to the participants of the Sixth Annual Boulder Conference on Legal Information: Teaching \& Scholarship (July 10-12, 2014, San Antonio, Texas) for their insights and feedback, especially Shawn G. Nevers, Head of Reference Services, Brigham Young University Clark Law School. I would also like to thank my colleagues at the Indiana University McKinney School of Law: Benjamin J. Keele, Research and Instructional Services Librarian, and Nicholas K. Georgakopoulos, Harold R. Woodard Professor of Law, for their helpful comments, along with Hannah Alcasid, Electronic Information and Data Support Technician, Ruth Lilly Law Library, for her creative talents and dedication to good design.

** Research and Instructional Services Librarian, Ruth Lilly Law Library, Indiana University Robert H. McKinney School of Law, Indianapolis, Indiana. 


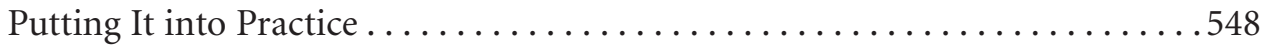

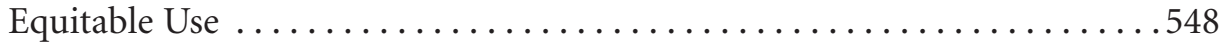

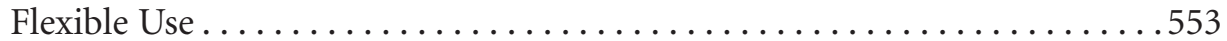

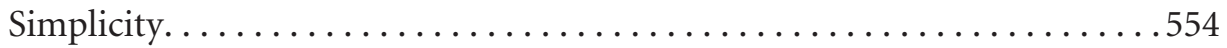

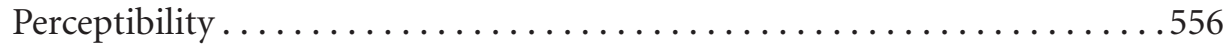

Tolerance for Error . . . . . . . . . . . . . . . . . . . . . . . . . . . . 559

Low Physical Demands . . . . . . . . . . . . . . . . . . . . 560

Appropriate Space and Size for Use . . . . . . . . . . . . . . . . 560

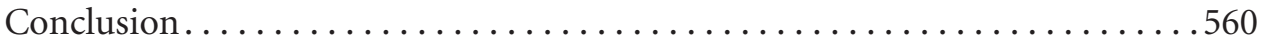

\section{Introduction}

I1 Haben Girma is a recent graduate of Harvard Law School; she is deaf and blind. When asked about the role of technology in her learning, she replied:

One of the biggest issues is definitely technology, and the funny thing is, technology has the potential to make life so much easier.... [W] hat I want to stress to universities is that when they invest in new technologies, when they build online learning tools, think about accessibility because there are small changes [they] can make that would make it easily accessible to hundreds and hundreds of students. ${ }^{1}$

Law schools would be wise to heed Girma's advice. The number of law students with sensory, motor, and cognitive impairments is increasing. ${ }^{2}$ At the same time, online instruction is making inroads into legal education. ${ }^{3}$ Course websites, e-texts, blogs, LibGuides, discussion forums, class Facebook pages, and other manifestations of the digitizing of legal education are cropping up more and more frequently. As Girma suggests, online instruction holds many promises for people with impairments. Digital information is nothing but 1 s and 0s capable of being rendered in many different ways, including formats that reach the disabled. The tools exist that would allow disability to recede and usability to take center stage. Unfortunately, many educators who are developing materials for online instruction do not know what is needed or how the tools work. There is much to learn.

1. The State of Things: First Deaf-Blind Student at Harvard Law Pursues Dreams, N.C. PuB. RADIO (Nov. 1 2013), transcript available at http://wunc.org/post/first-deaf-blind-student-harvard -law-pursues-dreams.

2. In 2011, more than 5000 students in law schools accredited by the American Bar Association (ABA) sought accommodations for a disability, an increase in both number and percentage over previous years. The number seeking accommodations in 2009-2010 was 4941. Not only did the raw number of accommodation-seeking students grow, but the percentage increased as well, even as the total number of law students went up. ABA Comm'n on MEnTAL \& Physical Disability LaW, ABA DisABILITY STATISTICS REPORT 1 (2011), available at http://www.americanbar.org/content/dam/aba /uncategorized/2011/20110314_aba_disability_statistics_report.authcheckdam.pdf. The number of students seeking accommodations is not the same as the number of students with disabilities, but since students do not have to identify themselves as disabled, the accommodations number is the statistic available. Given stigmas surrounding disability, the actual number of students with some level of disability is likely higher.

3. The ABA does not accredit any online JD programs, but a student seeking a JD may take up to twelve credits online (i.e., "distance education") according to ABA accreditation standard 306. AM. Bar A'ssn, 2013-2014 ABA Standards and Rules of Procedure for the Approval of Law Schools 27 (2013). 
I2 This article is a primer on the work needed to ensure that accessibility is achieved as law schools develop online instruction. It also explores the relationship between accessibility standards and the broader principles of universal design, concluding that universal design is an effective paradigm for approaching accessibility issues. Universal design is effective because it pursues usability, abating the concept of disability and the segregation that often accompanies it.

I3 The section that follows sets the stage by recounting two scenarios from the Indiana University Robert H. McKinney School of Law, with discussion of the knowledge and implementation of accessibility features in online instructional materials. The next section provides an overview of various impairments and their effects on a user's experience of the online environment. Next is a review of the laws relevant to accessibility with attention to their potential application to online instruction, along with standards used to guide accessibility compliance. The article then explores the concept of universal design and its guiding principles, followed by a discussion of how to use the universal design principles to organize and better understand accessibility standards and practices. The final section briefly summarizes the discussion and encourages law librarians and professors to become knowledgeable and skilled in universal design for online materials to benefit all their students.

\section{For Want of Awareness}

I4 In 2011, the librarians at the Indiana University Robert H. McKinney School of Law began teaching legal research to second-year law students in a required, forcredit, online course. After many iterations, the course now consists of eight lessons. Each lesson contains several "pages" of text, graphics, and screencasts (some interactive, some not) covering the week's topic, followed by a research assignment. All materials are delivered online, and the answers to the assignment are recorded online through the university's learning management system (LMS). ${ }^{4}$

I5 Getting the course up and running, improving it, and keeping the material up to date has taken a tremendous amount of time. At first, it was all we could do to get the instruction ready and stay on top of the grading. Our earliest efforts to ensure accessibility involved simply making a print version of any slideshow presentations available. With growing awareness of the needs of the disabled, the requirements of the law, and the tools available for compliance, we have made great strides.

I6 In January 2013, a law professor at Indiana University Robert H. McKinney School of Law began a class blog using Google's Blogger platform. He now uses a blog for each of his classes. The blogs contain posts regarding readings and upcom-

4. Indiana University (IU) uses an LMS called Oncourse, a Sakai-based system made proprietary to IU. As of mid-2014, IU is beginning implementation of Canvas, which will incrementally replace Oncourse, but any LMS-specific observations in this article are based on use of Oncourse. Accessibility considerations are universal to all LMSs, although their handling will differ across platforms. Rather than exploring the details of accessibility accommodations in the various LMSs such as Blackboard and Desire2Learn, this article seeks to raise awareness and suggest generalized best practices, leaving implementation in specific contexts to the individual. 
ing discussions, reviews of material, assignments, and links to outside readings and news items. Students are encouraged to comment on his posts but are not required to. In addition, the professor requires students to submit written work. The professor then selects two of the written pieces and posts them anonymously on the blog along with his own constructive comments regarding both content and form.

I7 The professor admits that he knew nothing about planning and designing for accessibility when he began his first class blog. As with so many of us, the idea simply never occurred to him. He had not, at least to his knowledge, ever had a student with visual, hearing, or motor impairments such that reading a blog would be difficult. He is now in the process of learning more about the tools available to ensure that his class blogs comply with accessibility standards.

I8 In both these situations, concern about accessibility came very late in the process and required backtracking, reworking of material, and duplication (even triplication) of effort. This is not unusual. Consider, for example, the experience of the law librarians at the U.S. Supreme Court Library when Justice Sandra Day O'Connor hired Isaac Lidsky, a blind attorney, as her law clerk for the October 2008 term. ${ }^{5}$ The Supreme Court had never had a visually impaired clerk before, and the librarians underwent a crash course in accessibility to make it possible for Lidsky to do his job. ${ }^{6}$ In the end, they were quite successful in helping him, but their accessibility expertise came only in the wake of demand. ${ }^{7}$

I9 Planning for accessibility in online materials ahead of time is both more efficient and more cost-effective in the long run. Our failure to plan ahead and achieve greater accessibility is due in part to a lack of awareness and involvement. Many of us creating online materials do not know the issues or the remedies. The following discussion may help alleviate this unfamiliarity so that online instructors will be better equipped to plan for accessibility at the outset.

\section{Understanding Impairments}

I10 Disabilities vary widely and do not come with one-size-fits-all solutions. An instructor cannot begin to create materials with maximum usability without a sense of the range of impairments and assistive technologies. ${ }^{8}$

\section{Visual Impairments}

\$11 Creating access for people with visual impairments affects just about every aspect of online instruction development. When considering visual impairments, many people think of total blindness. While certainly of vital importance in

5. Linda C. Corbelli \& Melissa A. Williams, Working with Isaac: A Visually Impaired Law Clerk and the Supreme Court, LAw LiBr. LighTS, Spring 2010, at 1.

6. The Supreme Court librarians quickly learned which document formats work with a JAWS screen reader and how to convert cleanly from one format to another, how difficult it is for a visually impaired person to navigate online forms, and what hassles are involved in trying to get electronic rather than print copies of some treatises. Id. at 3-5.

7. Fortunately for the rest of us, the librarians have shared their experiences so that we can learn ahead of time what they had to do on the fly. See id.

8. The information in this review of impairments is widely available. For a useful summary, see Jeremy J. Sydik, Design Accessible Web Sites: Thirty-six Keys to Creating Content for All AudiENCES AND PlatForms 17-25 (2007). 
designing for accessibility, total blindness is not the only visual impairment to consider. Legal blindness exists when someone's visual acuity is 20/200 or less. Low vision is defined as visual acuity of 20/70 or less. Many people have difficulty distinguishing certain colors or contrasts, and some people respond to certain visual stimuli with seizures.

I12 People with vision impairments may use a number of different technologies to assist them in accessing online materials. Screen readers, such as JAWS, ${ }^{9} \mathrm{Hal},{ }^{10}$ VoiceOver ${ }^{11}$ and Orca, ${ }^{12}$ read text from web pages aloud to the user. ${ }^{13}$ Those who read Braille may choose instead to use a refreshable Braille display, a device that "reads" the text on a web page and presents it to the user on the Braille device. These technologies rely on text, and to be fully effective there must be text equivalents for all non-decorative images-buttons, pictures, graphs, charts, and so on.

I13 For those with low vision, magnification may be sufficient. This can be accomplished with a large monitor, software magnifiers such as Zoom Text, or simply using a low resolution such as $800 \times 600$ on a regular monitor. This must be taken into consideration when designing online materials.

I14 Difficulty in distinguishing colors ranges from an inability to distinguish red and green, blue and yellow, dark shades of color from black, and nearly matching colors. Many meanings and distinctions in information can be conveyed by color, ${ }^{14}$ but for those who cannot make these distinctions, the information is lost. Instructors creating online materials should not rely on color distinctions alone to convey information but rather pair color with other distinctions such as size, typeface, placement, and textual explanations.

$\mathbb{1 1 5}$ Flickering and light patterns that can trigger seizures are generally the result of video included on a web page, for example, a video of a moving train where light and shadow flash back and forth. ${ }^{15}$ The best solution to this is to include such videos only when they are essential to the instruction being conveyed. If a flickering video is essential, the next-best solution is to have it load in a stopped state and then include a warning at the top of the web page as well as an alternative description of the content for those who are unable to watch the video.

9. See Jaws Headquarters, FreEDOM SCI., http://www.freedomscientific.com/jaws-hq.asp (last visited Feb. 18, 2015).

10. See Hal Screen Reader, Intelligent Speech \& Braille for Windows, SynAPSE AdAPTIVE, http://www .synapseadaptive.com/dolphin/hal.htm (last visited Feb. 18, 2015).

11. See Accessibility: VoiceOver for OS X, APPLE, http://www.apple.com/accessibility/osx/voiceover/ (last visited Feb. 18, 2015); Accessibility: VoiceOver for iOS, ApPLE, http://www.apple.com/accessibility /ios/voiceover/ (last visited Feb. 18, 2015).

12. Willie Walker, Orca-Take the Killer Whale for a Ride, Linux J. (Mar. 1, 2008), http://www .linuxjournal.com/magazine/orcamdashtake-killer-whale-ride.

13. To better understand what a screen reader sounds like, see Blind Ambition (Harvard Law Documentary Studio 2013), available at http://vimeo.com/69119995.

14. See, e.g., Cynthia A. Brewer, Color Use Guidelines for Mapping and Visualization, in VisualizaTION IN Modern CARTOGRAPHY 123 (A.M. MacEachren \& D.R.F. Taylor eds., 1994); see also Drew Skau, Seeing Color Through Infographics and Data Visualizations, VisuaL.LY (Apr. 2013), http://blog.visual.ly /seeing-color-through-infographics-and-data-visualizations/.

15. Seizure Disorders, WeвAIM, http://webaim.org/articles/seizure/ (last updated Oct. 12, 2012). 
\16 Some people include flashing effects on a web page to draw the viewer's attention to certain information. Designers now avoid this extra flicker as it is annoying to most users and dangerous to some.

\section{Hearing Impairments}

I17 As with visual impairments, hearing impairments run along a spectrum as well, from total deafness to loss of hearing only within certain tonal ranges, with many variations in between. Captioning and transcripts of auditory material can help these students. Captioning is text that is synchronized to the audio track of a video, while transcripts exist outside the video and are not synchronized. Another distinction can be made between captions and subtitles. Subtitles are limited to spoken words, while captioning attempts to capture other sounds in addition to speech, such as laughter or music. ${ }^{16}$ Another option is to include a sign language interpreter along with the video, though this is helpful only to those who understand sign language.

\section{Mobility Impairments}

I18 Mobility impairments arise when a person loses range in or control over bodily motion. Causes of mobility impairments can include everything from arthritis to paralysis to missing limbs to Parkinson's disease. Those with mobility impairments may have difficulties using a mouse or a keyboard and use alternative technologies that mimic mouse or keyboard actions. These technologies are often a bit slower than a mouse or keyboard, so it is important to limit or eliminate anything relying on a timing effect. Precise navigation to small areas is also challenging. This translates to a need for hotspots that are as large as possible. ${ }^{17}$

\section{Cognitive Impairments}

I19 Cognitive impairments are any kind of learning disability, perceptual disorder, or processing disorder. Examples include everything from dyslexia to an inability to distinguish between foreground and background. Attention deficit disorder and attention deficit hyperactivity disorder are increasingly common among students in higher education. ${ }^{18}$ Principles of good design such as logical

16. SYDIK, supra note 8 , at 20-22.

17. Id. at 22 .

18. Melana Zyla Vickers, Accommodating College Students with Learning Disabilities: ADD, ADHD, AND DYSLEXIA (2010), available at http://www.popecenter.org/acrobat/vickers-mar2010 .pdf. Several articles have been written about law students with ADD and other learning disabilities. Among them are Robin A. Boyle, Law Students with Attention Deficit Disorder: How to Reach Them, How to Teach Them, 39 J. MARSHALl L. Rev. 349 (2006); Leah M. Christensen, Law Students Who Learn Differently: A Narrative Case Study of Three Law Students with Attention Deficit Disorder (ADD), 21 J.L. \& Health 45 (2008); Leah M. Christensen, Legal Reading and Success in Law School: The Reading Strategies of Law Students with Attention Deficit Disorder (ADD), 12 SCHOLAR 173 (2010); Ruth Colker, Extra Time as an Accommodation, 69 U. PITT. L. Rev. 413 (2008); Susan E. McGuigan, Documenting Learning Disabilities: Law Schools' Responsibility to Set Clear Guidelines, 36 J.C. \& U.L. 191 (2009); Suzanne E. Rowe, Learning Disabilities and the Americans with Disabilities Act: The Conundrum of Dyslexia and Time, 15 LEgAL Writing: J. LegAL Writing InST. 165 (2009). 
organization, readable text, strong contrast, and proper spacing go a long way in helping students with cognitive impairments. ${ }^{19}$

\section{Nonnative Language Speakers}

I20 While not a true impairment, being new to the language of the instructional material can certainly be a barrier to learning. Students whose native language differs from the content of the material may be unable to understand idioms, slang, or even straightforward text if it is rendered in certain fonts. They may also struggle to follow the spoken language in a video or a podcast due to speed, vocabulary, or the speaker's accent. Many of the techniques used to help those with hearing or cognitive impairments are useful to nonnative language speakers as well. For instance, captions and transcripts can help a student whose reading ability in the target language is better than her auditory ability. The same is true for logical organization, readable text, and clear navigation.

\section{Accessibility Laws and Standards}

I21 Several federal laws and numerous state laws address impairments by prohibiting discrimination and requiring accommodations. Of these, the Rehabilitation Act of 1973 and its 1998 amendments are the most relevant to online instruction in higher education. As discussed below, the Americans with Disabilities Act (ADA) and its amendments focus on access to physical rather than virtual spaces. ${ }^{20}$ Most recently, the Twenty-first Century Communications and Video Accessibility Act of 2010 (CVAA) targets accessibility to digital content, but it applies to hardware, software, and video content producers and providers, and not, generally speaking, to colleges and universities.

I22 There are also accessibility standards to follow. The most comprehensive and widely used are the Web Content Accessibility Guidelines (WCAG). The U.S. government has its own standards, and other institutions have issued simpler guidelines.

\section{Section 504 of the Rehabilitation Act of 1973}

I23 Although it did not garner the attention that other civil rights laws received, the Rehabilitation Act of 1973 was a milestone in the efforts to improve opportunities for the "handicapped." ${ }^{21}$ Earlier civil rights laws had established a norm of including nondiscrimination clauses applicable to federal contractors and other entities receiving federal funds. By extrapolation, it made sense to include language

19. SYDIK, supra note 8 , at 23-24.

20. For a comprehensive study of the disability discrimination laws and their effect on higher education, see Laura Rothstein, Higher Education and Disability Discrimination: A Fifty Year Retrospective, 36 J.C. \& U.L. 843 (2010).

21. Rehabilitation Act of 1973, Pub. L. No. 93-112, $\$ \$ 501-510,87$ Stat. 355 (codified as amended at 29 U.S.C. $\$ \$ 791-794 f$ ). The Rehabilitation Act replaced the Vocational Rehabilitation Act, a law originally passed in 1920 and amended multiple times in the interim. 
disallowing discrimination on the basis of "handicap" in the 1973 Rehabilitation Act. $^{22}$

I24 Section 504 of the Rehabilitation Act requires compliance by all entities that receive federal funding in any way, including universities and colleges. Under section 504 (as amended), "[n] o otherwise qualified ${ }^{23}$ individual with a disability ... shall, solely by reason of her or his disability, be excluded from the participation in, be denied the benefits of, or be subjected to discrimination under any program or activity receiving Federal financial assistance." 24 To have a "disability," a person must "(1) [have] a physical or mental impairment which substantially limits one or more of such person's major life activities; (2) ... [have] a record of such impairment; or (3) [be] regarded as having such an impairment." Major life activities include "functions such as caring for one's self, performing manual tasks, walking, seeing, hearing, speaking, breathing, learning, and working." ${ }^{25}$

I25 Courts have held that this mandate requires colleges and universities to make "reasonable accommodations" to allow students to participate in the educational program. ${ }^{26}$ Reasonable accommodations are those that ensure equal opportunity for participation and access to the benefits of the institution's programs without causing undue hardship for the institution. Undue hardship arises from accommodations that would (1) require fundamental changes to the nature of the educational program; (2) pose a safety risk to the individual or others; or (3) create an undue administrative or financial burden. ${ }^{27}$ For example, in Southeastern Community College $v$. Davis, the U.S. Supreme Court held that a nursing school was allowed to deny admission to a deaf applicant because the program's requirements included a clinical phase. To accommodate the deaf student, the school would either have to provide constant supervision and assistance during this phase or eliminate the requirement. The court held that both of these options were too substantial to be required, though it left the door open for requiring lesser accommodations. ${ }^{28}$

\section{Amendments to the Rehabilitation Act}

I26 In 1998, Congress amended section 508 (but not section 504) of the Rehabilitation Act to require that all federal agencies and departments ensure that all federal employees and members of the public seeking information from a federal entity have access to and use of electronic information regardless of any disability. ${ }^{29}$

22. Id. \$\$ 503-504 (codified at 29 U.S.C. \$\$ 793-794).

23. Regulations promulgated by the Department of Education interpret "otherwise qualified" to mean that a student must meet "the academic and technical standards requisite to admission or participation in the recipient's educational program or activity." 34 C.F.R. $\$ 104.3(l)(3)(2014)$. In other words, an individual must be able to meet all of a program's requirements in spite of his or her handicap. Id. $\$ 104$ app. A.

24. 29 U.S.C.A. $\$ 794$ (West, Westlaw current through P.L. 113-74 (excluding P.L. 113-66 and $113-73))$.

25. 34 C.F.R. $\$ 104.3(j)(2)($ ii) (2014).

26. Southeastern Cmty. Coll. v. Davis, 442 U.S. 397 (1979).

27. Mills v. Bd. of Educ., 348 F. Supp. 866 (D.D.C. 1972).

28. Southeastern Cmty. Coll., 442 U.S. at 398.

29. Workforce Investment Act of 1998, Pub. L. No. 105-220, 112 Stat. 936 (codified at 29 U.S.C. $\$ 794 d)$. 
Under this amended section 508, federal agencies and departments have to make sure that their websites, databases, portals, electronic documents, and all other electronic information are as equally accessible to the disabled as to the nondisabled. This provision leaves no doubt - at least for federal agencies and departmentsabout accessibility requirements and the Internet, filling a potential gap that had arisen with advances in technology that were inconceivable in 1973.

I27 That said, these protections have not been specifically extended to entities receiving federal funding under section 504, leaving open the possibility for the argument (albeit small and unlikely to succeed) that a college or university is not required to make its electronic materials accessible. However, the language of section 504 reads: "No otherwise qualified individual with a disability . . shall, solely by reason of her or his disability, be excluded from the participation in, be denied the benefits of, or be subjected to discrimination under any program or activity receiving Federal financial assistance . . ." ${ }^{30}$ A search for litigation on this issue returned no relevant appellate decisions, but the National Association for the Deaf filed a lawsuit in February 2015 against Harvard and MIT for failing to provide captioning in online video courses. The complaint asserts violations of both the Rehabilitation Act and the Americans with Disabilities Act. ${ }^{31}$ If previous scholarship is on the mark, then there is little room for doubt that accessibility features in electronic instructional materials_-along with websites, databases, and other electronic tools for learning-will be required, especially under the Rehabilitation Act. ${ }^{32}$ These legal particulars, of course, do not even begin to address the pedagogical imperative to reach students with appropriate instruction.

\section{Americans with Disabilities Act}

I28 The ADA was signed into law by President George H.W. Bush in 1990. At the time, the Internet was in a nascent state and was not considered by Congress as a source of discriminatory practices. The ADA, as a product of its time, focused on access to physical locations and in-person activities.

I29 Under title II of the ADA, "no qualified individual with a disability shall, by reason of such disability, be excluded from participation in or be denied the

30. 29 U.S.C.A. $\$ 794$ (West, Westlaw current through P.L. 113-74 (excluding P.L. 113-66 and 113-73)).

31. Complaint, Nat'l Ass'n of the Deaf v. Harvard Univ., No. 3:15-cv-30023 (D. Mass. Feb. 12, 2015).

32. See Nina Golden, Access This: Why Institutions of Higher Education Must Provide Access to the Internet to Students with Disabilities, 10 VAND. J. ENT. \& TECH. L. 363 (2008) (asserting that the language of section 504, even as it stands, would require accessibility in electronic resources given how vital they are to higher education); see also Judith Stilz Ogden \& Lawrence Menter, Inaccessible School Webpages: Are Remedies Available?, 38 J.L. \& EDUC. 393 (2009). The situation is somewhat different for a private college receiving no federal funding (there are a few like this). This school would be subject only to the ADA. Under the ADA, there has been some disagreement as to whether a website or other electronic information constitutes a "place" of public accommodation so as to require reasonable accommodations for the disabled. See, e.g., Nat'l Fed'n of the Blind v. Target Corp., 452 F. Supp. 2 d 946 (N.D. Cal. 2006). For an assertion that the Constitution requires accessibility in electronic resources, see Joshua L. Friedman \& Gary C. Norman, The Norman/Friedman Principle: Equal Rights to Information and Technology Access, 18 TEX. J. C.L. \& C.R. 47 (2012). 
benefits of the services, programs, or activities of a public entity, or be subjected to discrimination by any such entity." ${ }^{33}$ State colleges and universities as well as community and city colleges fall under title II. In essence, the law extends the same protections provided by section 504 of the Rehabilitation Act, but does so regardless of federal funding.

\30 Title III of the ADA prohibits disability discrimination on the part of public accommodations and services, even when privately owned. ${ }^{34}$ To be subject to title III, an entity must affect commerce and fall into one of a several categories. Among these categories are private schools, both undergraduate and postgraduate. ${ }^{35}$ Like section 504 of the Rehabilitation Act, the ADA requires schools to make reasonable accommodations for otherwise qualified individuals. These include "auxiliary aids and services" such that "no individual with a disability is excluded, denied services, segregated or otherwise treated differently than other individuals ... unless the entity can demonstrate that taking such steps would fundamentally alter the nature of the good, service, facility, privilege, advantage, or accommodation being offered or would result in an undue burden." ${ }^{36}$

I31 Despite similarities to the Rehabilitation Act, the applicability of the ADA to websites and other electronic information sources has been debated due to the ADA's emphasis on physical location. In Young v. Facebook, ${ }^{37}$ the district court held that Facebook was not required to provide accommodations because it was a virtual space with no nexus to a physical space. Similarly, in National Federation of the Blind v. Target Corp. ${ }^{38}$ the court held that the plaintiff had stated a claim under title III of the ADA regarding the lack of accessibility of Target's website, but only insofar as the inaccessibility "impedes the full and equal enjoyment of goods and services offered in Target stores. To the extent that Target.com offers information and services unconnected to Target stores, which do not affect the enjoyment of goods and services offered in Target stores, the plaintiffs fail to state a claim . . . " 39 How these rulings play out in the suit against Harvard and MIT remains to be seen.

\section{Amendments to the ADA}

I32 When crafting the original ADA, Congress used the definition of disability that had been used for nearly two decades in the Rehabilitation Act. Courts, however, construed the ADA definition more narrowly. For example, in Sutton v. United Air Lines, the U.S. Supreme Court stated that the existence of a disability was to be determined in its mitigated state. ${ }^{40}$ As a result, a person whose disability can be ameliorated may be determined not to have a disability. Three years later, in Toyota Motor Manufacturing, Kentucky v. Williams, the Supreme Court also declared that the standard for determining the existence of a disability must be a demanding

\footnotetext{
33. 42 U.S.C. $\$ 12132(2012)$.

34. See id. $\$ 12182(\mathrm{a})$.

35. See id. $\$ 12181(7)(\mathrm{j})$.

36. See id. $\$ 12182(\mathrm{~b})(2)(\mathrm{A})(\mathrm{iii})$.

37. 790 F. Supp. 2d 1110 (N.D. Cal. 2011).

38. 452 F. Supp. 2d 946 (N.D. Cal. 2006).

39. $I d$. at 956.

40. 527 U.S. 471 (1999).
} 
one. ${ }^{41}$ This declaration led many lower courts to find a lack of disability, never reaching the issue of discrimination.

I33 The ADA Amendments Act of 2008 (ADAAA) was designed to overturn these decisions and reestablish a broad interpretation for the definition of disability. ${ }^{42}$ The amendments retained the basic definition of "disability" as an "impairment that substantially limits one or more major life activities, a record of such an impairment, or being regarded as having such an impairment," but it changed the interpretations of several terms in this definition. One of these was "major life activities." In a nonexclusive list, Congress included "caring for oneself, performing manual tasks, seeing, hearing, eating, sleeping, walking, standing, lifting, bending, speaking, breathing, learning, reading, concentrating, thinking, communicating, and working." 43 The amendments do not mention Internet use or electronic communication as major life activities. Arguably learning, reading, communicating, and perhaps even thinking now require appropriate access to electronic information resources, but as evidenced by the Young v. Facebook and National Federation of the Blind $v$. Target decisions, this broad definition of disability does not displace the requirement of a nexus with a physical place. ${ }^{44}$

\section{Twenty-first Century Communications and Video Accessibility Act of 2010}

\34 Two years after the ADAAA, President Obama signed the CVAA into law. ${ }^{45}$ This law begins to establish the rights of those with disabilities to access and use the Internet. Title I of the CVAA focuses on communications services and equipment, requiring that virtually all communication software (e.g., Internet browsers, instant messaging services) and hardware (e.g., smartphones, tablets) be made accessible to all users, with special attention paid to video playback and emergency information capabilities. As an example, Internet browsers on phones must be accessible to the visually impaired. ${ }^{46}$ Title II of the CVAA requires captioning on all video shown online if the video was first shown on television. In addition, all devices with Internet connectivity, regardless of size, must be capable of displaying closed captioning and other available video description. ${ }^{47}$ At this point, video created exclusively for communication via the Internet is exempted from the captioning requirements.

I35 Since the CVAA is directed primarily at hardware, software, and television producers, the law does not have significant legal impact on creators of online

41. 534 U.S. 184 (2002).

42. For a discussion of the ADAAA and its impact on law schools, see What the ADA Amendments and Higher Education Acts Mean for Law Schools, 18 AM. U. J. GENDER Soc. PoL'y \& L. 13 (2009). See also Wendy F. Hensel, Rights Resurgence: The Impact of the ADA Amendments Act on Schools and Universities, 25 GA. ST. U. L. REV. 641 (2009).

43. ADA Amendments Act of 2008, Pub. L. No. 110-325, § 4, 122 Stat. 3553, 3555.

44. See Young v. Facebook, 790 F. Supp. 2d 1110 (N.D. Cal. 2011); Nat'l Fed'n of the Blind v. Target Corp., 452 F. Supp. 2d 946 (N.D. Cal. 2006).

45. Twenty-first Century Communications \& Video Accessibility Act of 2010, Pub. L. No. 111260, 124 Stat. 2751.

46. Id. $\$ 104$.

47. Id. $\$ 203$; see also Jonathan Lazar \& Paul Jaeger, Reducing Barriers to Online Access for People with Disabilities, Issues ScI. \& TECH., Winter 2011, at 69, available at http://www.issues.org/27.2/lazar .html. 
education materials, but it does set targets with which we can comply. Consider a video - a lecture or a screencast—created by a professor for use in an online class. Both best practices and section 504 of the Rehabilitation Act indicate that the professor should provide a text alternative for the audio track. From my own experience, I know that a transcript is a relatively easy solution. However, under the CVAA, the audio alternative of choice is captioning instead of a transcript. Furthermore, this captioning is expected to match the quality of that done for television in terms of "completeness, placement, accuracy, and timing." ${ }^{48}$ Under already existing rules for television captioning, the user must be able to control captions' text color and opacity, size, font, background color and opacity, character edge attributes, and window color. ${ }^{49}$ To do this in videos created for an online class would likely take considerable work and depend on the sophistication of the video presentation software, but perhaps we can use these rules as an ideal for which to strive as we develop our awareness and skills to create the best experience for the student with audio limitations.

\section{State Laws}

\36 As of 2009, approximately fifteen states had statutes addressing website accessibility, and all fifty states had policies or guidelines on the subject. ${ }^{50}$ Although states' coverage varies, Oklahoma's law, passed in 2004, is typical in that it essentially adopts the standards of section 508, the section of the Rehabilitation Act that governs federal websites. ${ }^{51}$ Other states have looked to the WCAG ${ }^{52}$ drawn up by the World Wide Web Consortium (W3C) or a hybrid of the WCAG and Section 508 standards. ${ }^{53}$ Given that these standards are not dramatically different in end result, the state standards and federal standards are generally closely aligned.

48. Closed Captioning on Television, FCC, http://www.fcc.gov/guides/closed-captioning (last visited Feb. 18, 2015); see also Issue Brief: CVAA Online Video Captioning Requirements and Deadlines, 3PlayMediA, http://info.3playmedia.com/rs/3playmedia/images/CVAA-Brief.pdf (last visited Feb. 18, 2015).

49. 47 C.F.R. $\$ 79.102$ (2014); see also Maria T. Browne et al., FCC Adopts Closed Captioning Rules for Online Video Programming, Davis Wright Tremaine (Jan. 17, 2012), http://www.dwt.com /FCC-Adopts-Closed-Captioning-Rules-for-Online-Video-Programming-01-17-2012/.

50. State E \& IT Accessibility Initiatives, GA. TECH RESEARCH InST., http://accessibility.gtri.gatech .edu/sitid/state_prototype.php (last visited Feb. 18, 2015).

51. OKla. Stat. Ann. tit. 62, $\$ 34.28$ (West, Westlaw current through Chapter 23 (End) of the First Extraordinary Session of the 54th Legislature (2013)). Other examples include Arizona, ARIZ. REV. StAT. ANN. $\$ 41-3532$ (West, Westlaw current through the First Regular and First Special Sessions of the Fifty-first Legislature), and California, CAL. GOV’T CODE $\$ 11135(\mathrm{~d})(2)$ (West, Westlaw current with urgency legislation through Ch. 1 of 2014 Reg. Sess. and all propositions on the 6/3/2014 ballot).

52. See, e.g., Universal Web Site Accessibility Policy for State Web Sites-Version 4.0, STATE OF CT. Weв SiTE ACCESSIBILITY COMM., http://www.access.state.ct.us/policies/accesspolicy40.html (last visited Feb. 18, 2015).

53. See, e.g., State of Michigan Look and Feel Standards for Web Applications and Sites (Jan. 2015), available at http://www.michigan.gov/documents/som/Look_and_Feel_Standards_302051_7 .pdf. 


\section{Industry Standards: Quality Matters, WCAG 2.0, Section 508}

I37 Many universities and other educational institutions, including my home institution of Indiana University, have adopted the Quality Matters (QM) rubric to guide the planning, designing, and reviewing of online courses. Standard 8 of the QM rubric addresses accessibility issues with only the most basic guidance in four specific areas of review. ${ }^{54}$

138 Within the scope of the first of these standards is the requirement that the instructor set up the course within an accessible learning management system (LMS). Furthermore, the instructor should provide information regarding the accessibility of the course materials and how to seek accommodation if any part is not accessible.

I39 The second, third, and fourth areas of review get to substantive design and content issues. Standard 8.3 is the most basic, incorporating design principles regarding layout, colors, fonts, and formatting as well as writing style. Standard 8.2 is the usual requirement to create text equivalents for all non-textual content (e.g., audio, video, images, and graphics). Then, standard 8.4 encourages designing for assistive technologies. The annotations in the QM rubric explain that this incorporates aspects such as navigation, metadata, and meaningful links. ${ }^{55}$

I40 The QM standard is valuable as a baseline check, especially for those instructors who are new to accessibility concerns, but it does not provide the guidance necessary to ensure that online materials are fully accessible. Fortunately, more specific standards are available.

I41 WCAG 1.0 was published and recommended to website and online content developers in 1999 by the W3C's Web Accessibility Initiative (WAI). ${ }^{56}$ WCAG 2.0 followed in 2008. ${ }^{57}$ The WCAG built on multiple sets of earlier guidelines written in the 1990s. Today, the WCAG are the primary standards by which accessibility compliance is planned, implemented, and measured. They have been adopted by the International Standards Organization, ${ }^{58}$ and the Canadian and Australian federal governments have endorsed WCAG 2.0 for all government web sites. ${ }^{59}$ Many

54. The four areas of review in standard 8 are:

1. The course employs accessible technologies and provides guidance on how to obtain accommodation.

2. The course contains equivalent alternatives to auditory and visual content.

3. The course design facilitates readability and minimizes distractions.

4. The course design accommodates the use of assistive technologies

Maryland Online, Quality Matters Rubric Workbook for Higher Education 18 (2011-2013 ed.).

55. Id. at 19 .

56. The W3C was founded in 1994 by Tim Berners-Lee, the author of the first web server and browser as well as the first version of HTML. The W3C is a consortium of universities, businesses, government entities, nonprofits, and individuals that develops and dispenses standards for the World Wide Web. Familiar examples of W3C standards include HTML and other markup languages as well as Cascading Style Sheets (CSS) and Resource Description Framework (RDF). Facts About W3C, W3C, http://www.w3.org/Consortium/facts (last visited Feb. 18, 2015).

57. W3C Web Standard Defines Accessibility for Next Generation Web, W3C (Dec. 11, 2008), http:// www.w3.org/2008/12/wcag20-pressrelease.html.

58. ISO/IEC 40500:2012, INT'L STANDARDS ORG. (Oct. 12, 2012), http://www.iso.org/iso/iso _catalogue/catalogue_tc/catalogue_detail.htm?csnumber $=58625$.

59. Web Guide, Austrl. Gov't (Apr. 1, 2011), http://webguide.gov.au/accessibility-usability /accessibility/; Standard on Web Accessibility, Treasury BD. of Can. SECretariat (Aug. 1, 2011), http://www.tbs-sct.gc.ca/pol/doc-eng.aspx?id=23601\&section=text. 
other governments have done likewise. ${ }^{60}$ Although the U.S. government has not specified the use of WCAG, complying with WCAG standards would satisfy the requirements of the $\mathrm{ADA}$ and the Rehabilitation Act and is playing a role in the refreshing of the section 508 standards. ${ }^{61}$

I42 The techniques of WCAG 2.0 have been criticized as ineffective ${ }^{62}$ and unrealistic $^{63}$ by some people in the accessibility field. One criticism states that the guidelines fail to address nearly half the problems encountered on websites. ${ }^{64}$ Another criticism states that WCAG 2.0 is a step backward in several ways. ${ }^{65} \mathrm{~A}$ third takes aim at the new hierarchy of compliance in WCAG 2.0. The A level is baseline compliance, with AA and AAA signifying higher levels of compliance. The A level has been criticized as leaving far too many barriers in place while the AAA level is essentially unachievable. It has been noted that individual pages may be AAA compliant, but AAA requirements can conflict with each other and with other guidelines, making compliance for an entire website more difficult than "find[ing] unicorns." 66

I43 For most of us creating online instructional materials, the basic criteria and techniques of WCAG can help us create lessons that are generally accessible to our students. ${ }^{67}$ Beyond this basic level, the WCAG become more complex and in many

60. Mark Rogers, Government Accessibility Standards and WCAG 2.0, POWERMAPPER SOFTWARE BlOG (Nov. 13, 2012), http://blog.powermapper.com/blog/post/Government-Accessibility-Standards .aspx.

61. Id.; The Future of WCAG-Maximising Its Strengths not Its Weaknesses, HASSELLINCLUSION (Jan. 7, 2013), http://www.hassellinclusion.com/2013/01/wcag-future/.

62. Christopher Power et al., Guidelines Are Only Half of the Story: Accessibility Problems Encountered by Blind Users on the Web, in ProceEDINGS of THE 2012 ACM ANNUAL CONFERENCE ON HUMAN FACTORS In COMPUTing Systems (2012), available at http://www.cs.york.ac.uk/hci/publications/001 /index.html. This paper describes a study in which techniques recommended in WCAG 2.0 did not solve certain problems faced by blind users.

63. Joe Clark, To Hell with WCAG 2, A LIST APART (May 23, 2006), http://alistapart.com/article /tohellwithwcag2. Clark also lashes out at the process behind the development of the WCAG, pointing out that both the deliberations and working documents were exclusionary.

64. Power et al., supra note 62.

65. Clark, supra note 63.

66. Mike Gifford, WCAG 2.0-A Journey Not a Destination, OPENCONCEPT (Sept. 29, 2010), http://openconcept.ca/blog/mgifford/wcag-20-aaa-journey-not-destination.

67. The WCAG 2.0 Quick Reference List is as follows:

1.1 Text Alternatives: Provide text alternatives for any non-text content so that it can be changed into other forms people need, such as large print, braille, speech, symbols or simpler language. 1.2 Time-based Media: Provide alternatives for time-based media.

1.3 Adaptable: Create content that can be presented in different ways (for example simpler layout) without losing information or structure.

1.4 Distinguishable: Make it easier for users to see and hear content including separating foreground from background.

2.1 Keyboard Accessible: Make all functionality available from a keyboard.

2.2 Enough Time: Provide users enough time to read and use content.

2.3 Seizures: Do not design content in a way that is known to cause seizures.

2.4 Navigable: Provide ways to help users navigate, find content, and determine where they are.

3.1 Readable: Make text content readable and understandable.

3.2 Predictable: Make Web pages appear and operate in predictable ways.

3.3 Input Assistance: Help users avoid and correct mistakes.

4.1 Compatible: Maximize compatibility with current and future user agents, including assistive technologies. 
instances highly technical, potentially putting them out of reach for educators who simply want to put class material online. ${ }^{68}$

I44 As alluded to above, section 508 of the Rehabilitation Act has its own set of regulations promulgated by the United States Access Board. ${ }^{69}$ The Access Board finalized these regulations in 2000, well before the release of WCAG 2.0. ${ }^{70}$ Thus the Access Board interpreted the section 508 regulations in conjunction with WCAG $1.0 .^{71}$ The Access Board is in the process of "refreshing" the section 508 standards,

How to Meet WCAG 2.0, W3C Web AcCessibility Initiative, http://www.w3.org/WAI/WCAG20 /quickref/Overview.php (last updated July 11, 2013). Ryan S. Overdorf of the American Association of Law Libraries Computing Services Special Interest Section provides excellent coverage of WCAG 2.0 and making websites accessible. See AALL CS-SIS WIKI, http://aallcssis.pbworks.com (web accessibility pages, pts. $1-4$, are listed in the sidebar) (last visited Feb. 18, 2015).

68. Evaluation tools are available to help determine accessibility compliance of a web page. The W3C WAI offers helpful information on understanding the use of and choosing an evaluation tool. See Selecting Web Accessibility Evaluation Tools, W3C WeB ACCESSIBILITY InITIATIVE, http://www.w3.org /WAI/eval/selectingtools.html (last visited Feb. 18, 2015).

69. The Access Board was established in 1973 to ensure physical access to federally funded buildings, parks, transportation projects, and other facilities. It now governs accessibility requirements for medical equipment, telecommunications, and information technology. Of the thirteen members of the board who do not represent federal agencies, the majority must have a disability of some kind. See About the U.S. Access Board, U. S. ACCESS BD., http://www.access-board.gov/the-board (last visited Feb. $18,2015)$.

70. These regulations are as follows:

(a) A text equivalent for every non-text element shall be provided (e.g., via "alt," "longdesc," or in element content).

(b) Equivalent alternatives for any multimedia presentation shall be synchronized with the presentation.

(c) Web pages shall be designed so that all information conveyed with color is also available without color, for example from context or markup.

(d) Documents shall be organized so they are readable without requiring an associated style sheet.

(e) Redundant text links shall be provided for each active region of a server-side image map.

(f) Client-side image maps shall be provided instead of server-side image maps except where the regions cannot be defined with an available geometric shape.

(g) Row and column headers shall be identified for data tables.

(h) Markup shall be used to associate data cells and header cells for data tables that have two or more logical levels of row or column headers.

(i) Frames shall be titled with text that facilitates frame identification and navigation.

(j) Pages shall be designed to avoid causing the screen to flicker with a frequency greater than 2

$\mathrm{Hz}$ and lower than $55 \mathrm{~Hz}$.

(k) A text-only page, with equivalent information or functionality, shall be provided to make a web site comply with the provisions of this part, when compliance cannot be accomplished in any other way. The content of the text-only page shall be updated whenever the primary page changes. (l) When pages utilize scripting languages to display content, or to create interface elements, the information provided by the script shall be identified with functional text that can be read by assistive technology.

(m) When a web page requires that an applet, plug-in or other application be present on the client system to interpret page content, the page must provide a link to a plug-in or applet that complies with $\$ 1194.21(\mathrm{a})$ through (1).

(n) When electronic forms are designed to be completed on-line, the form shall allow people using assistive technology to access the information, field elements, and functionality required for completion and submission of the form, including all directions and cues.

(o) A method shall be provided that permits users to skip repetitive navigation links.

(p) When a timed response is required, the user shall be alerted and given sufficient time to indicate more time is required.

36 C.F.R. $\$ 1194.22$ (2014).

71. Paragraphs (a) through $(\mathrm{k})$ were interpreted as consistent with WCAG 1.0 while paragraphs

(l) through ( $\mathrm{p}$ ) imposed higher standards than WCAG 1.0. See id. 
and has been since 2010 when the first draft of the proposed new rules was published. ${ }^{72}$ The new section 508 standards were expected in 2014. ${ }^{73}$ WCAG 2.0 is rumored to be a strong influence on the refreshed standards, as the Access Board wants the section 508 regulations to be as compatible as possible with global standards. ${ }^{74}$

\section{Universal Design}

I45 Laws and standards are helpful, but they do not solve everything. For instance, despite the fact that the United States has "the most comprehensive legislative approach to accessibility in the world," 75 implementation is weak and leaves gaping inaccessible holes. For example, a study of federal websites found that ninety percent of federal home pages did not comply with section 508 of the Rehabilitation Act. To make matters even worse, the federal compliance website itself (section508.gov) did not comply after its redesign in $2010 .^{76}$

I46 As for the standards, QM standard 8, while geared specifically toward online education, is simplistic and leaves many areas unaddressed. WCAG 2.0 is the gold standard, but its guidelines are extensive, complex, and highly technical in certain areas, leaving nonexperts confused. The section 508 regulations are somewhat dated and do not include more universal considerations such as layout, readability, and minimal distractions. In addition, they are in the process of revision and will soon be changing.

I47 The paradigm of universal design can help us cope with confusion as we wade through the laws and standards. ${ }^{77}$ Universal design is based on the idea that environments (virtual or physical) can be designed from the outset to accommodate all comers with the effect that any impairments are no longer barriers. In addition, the design is so usable that everyone benefits. Curb cuts offer an example of universal design in the built environment. It is not only those in wheelchairs who benefit from curb cuts; parents with strollers, pedestrians with groceries, travelers with suitcases, and commuters on bicycles all navigate the sidewalks and streets more easily thanks to this "accommodation." Closed captioning has had similar "unexpected" benefits. Not only can the hearing impaired enjoy television and movies, but people running on treadmills, waiting in airports, or watching a foreign film all benefit as well.

I48 The reverse is also true: difficult designs challenge everyone. Consider nesting "fly-out" menus - those drop-down menus where submenus expand to the side when you hover over an item. As Raymond Chen, author of Microsoft Developer's

72. 75 Fed. Reg. 13,457 (Mar. 22, 2010).

73. Rosemary Musachio, A Facelift for Section 508, InTeractive AcCeSSIBILITY (Mar. 14, 2013), http://www.interactiveaccessibility.com/blog/facelift-section-508.

74. Id.

75. Lazar \& Jaeger, supra note 47 , at 76.

76. $I d$.

77. For a discussion of universal design as it applies to teaching in the traditional law school classroom, see Meredith George \& Wendy Newby, Inclusive Instruction: Blurring Diversity and Disability in Law School Classrooms Through Universal Design, 69 U. PгтT. L. Rev. 475 (2008). 
Network's “The Old New Thing” blog, explains, fly-out nesting menus turn navigation "into one of those mouse dexterity games where you have to guide your character through a maze without hitting any of the walls or you die and have to start over." ${ }^{78}$ For those with vision or motor skill impairments, the maze might as well be a labyrinth with walls that are continually shifting.

I49 Robert Mace, an architect, is credited as the originator of "universal design," at least as an articulated design theory. ${ }^{79}$ Mace's work grew out of firsthand experience. At age nine, Mace contracted polio and spent the rest of his days in a wheelchair. ${ }^{80}$ Mace defined universal design as " $[\mathrm{t}]$ he design of products and environments to be usable by all people, to the greatest extent possible, without the need for adaptation or specialized design." ${ }^{81}$ Although Mace's definition has been criticized as simplistic, ${ }^{82}$ its foundational idea-that good design benefits most people regardless of their particularities-is profound in its simplicity yet rich in challenges:

The goal of universal design extends beyond eliminating discrimination toward people with disabilities. A universal design benefits everyone or, at least, a large majority. Moreover, to avoid stigma, it engages the aesthetic realm as well as the pragmatic because it has to appeal to everyone. Universal design is about dealing with barriers as artists or scientists would. It demands creative thinking and a change in perspective. It is not sufficient merely to apply design criteria in accessibility regulations in a mechanistic way. Often a change in perspective is needed. ${ }^{83}$

I50 Perhaps the most profound realization in universal design is that people are labeled as "disabled" when the environment in which they must function does not suit their abilities. When we design environments for universal use, the meaning of "disabled" begins to disappear. Take, for example, the Hall of Remembrance at the Holocaust Memorial in Washington, D.C. The Hall is a sunken space, and the design includes only stairs to reach the floor of the Hall. A lift has been installed in rather obtrusive fashion, but does not fit well because it was not planned as part of the design. Should "you enter during a quiet part of [a] ceremony, all eyes would be on you as you use this lift, and its noise would ruin the spirituality of the event. You would become a spectacle, the object of pity and/or annoyance." ${ }^{84}$ Contrast this with the graceful interweaving of steps and ramps in Vancouver's Robson Square, ${ }^{85}$

78. Raymond Chen, Nested Menus Are a Usability Nightmare, The Old New Thing (Aug. 23, 2007, 10:00 AM), http://blogs.msdn.com/b/oldnewthing/archive/2007/08/23/4517137.aspx.

79. See Ronald L. Mace, Universal Design: Barrier Free Environments for Everyone, 33 DESIGNER's WEST 147, 147 (1985).

80. Wolfgang Saxon, Ronald L. Mace, 58, Designer of Buildings Accessible to All, N.Y. TimES, July 13,1998 , at B9.

81. Mace, supra note 79 , at 147.

82. Robert Imrie \& Peter Hall, Inclusive Design: Designing and Developing Accessible EnviRONMENTS 16-17 (2001); EdWARd Steinfeld \& JORDANA MAISEl, Universal Design: Creating InClUSIVE ENVIRONMENTS 28-29 (2012).

83. STEINFELD \& MAISEL, supra note 82 , at 43.

84. Id.

85. See photos and discussion at Eight Amazing Examples of Ramps Blended into Stairs, TwISTED SIFTER (June 12, 2012), http://twistedsifter.com/2012/06/ramps-blended-and-integrated-into-stairs/. 
an environment where "accessibility features" are so much part of the design that no one has to experience the ostracism of "disability." 86

\section{Putting It into Practice}

I51 The Center for Universal Design at North Carolina State University, founded by Ronald Mace, urges seven principles of universal design: equitability, flexibility, simplicity, perceptibility, tolerance for error, low physical demands, and provision of appropriate size and space. ${ }^{87}$ These principles can help us make sense of the many accessibility standards by providing a concrete and meaningful framework. ${ }^{88}$

\section{Equitable Use}

I52 The principle of equitable use suggests that materials be designed so that everyone can make use of the same interface and features. Practices that fall under this principle include the following.

\section{Information on Accommodations}

I53 Information on accessibility features should be made available to everyone up front and in one location. This provides all students with an idea of how the various materials can work in a variety of situations, increasing students' options and allowing them the greatest possible flexibility. Information to make available can include how to navigate the site, what browsers work best, how to access video transcripts or print versions of online quizzes, how to control timed media, and when audio is present and how to turn it on or off.

I54 Some of the accessibility features in online instruction will be expected and obvious to the students who need them most, but for nonobvious features or for students who might benefit from obvious features but not normally use them, instructors can communicate their availability in situ as well as in separate documentation. For example, in the materials for the online legal research class discussed above, ${ }^{89}$ when a video is embedded on a page, I add a well-labeled link that opens the video in a new window where the display will be larger. I also spell out how to get to text equivalents of the audio. The paragraph preceding the video reads, "You can view the presentation on this page or, for easier viewing, go full screen in a separate window. In the presentation player itself, the Notes tab contains

86. Jay Dolmage, Disability, Usability, Universal Design, ACADEMIA.EDU, https://www.academia .edu/1569909/Disability_Usability_Universal_Design (last visited Feb. 18, 2015).

87. Bettye Rose Connell et al., The Seven Principles of Universal Design, NAT'L CTR. FOR UNIVERSAL Design, N.C. StATE UnIV. (Apr. 1, 1997), http://www.ncsu.edu/project/design-projects/sites/cud /content/principles/principles.html.

88. See Hadi Rangin, How-To Guide for Creating Accessible Online Learning Content, WeB ACCESSIBILITY FOR ONLINE LEARNING (last visited Feb. 18, 2015). Applying the paradigm of universal design outside the field of architecture is not unusual. It is commonly applied to both web design and education (Universal Design in Learning or UDL). For examples, see Wendy Chisholm \& MatT MaY, Universal Design for Web Applications 51-75 (2009); Universal Design in Higher Education: From Principles to Practice (Sheryl E. Burgstahler \& Rebecca C. Cory eds., 2008).

89. See supra II 4. 
the text of the audio, and a print version is available under Resources." The line below then contains a second link- Open video in a new window/tab-in case the first is overlooked.

\section{Judicious Use of Features Within an LMS}

I55 Online classes are typically housed within a LMS. Most instructors do not control the basic functioning of the LMS, though which features are used within a class can be at the instructor's discretion. Some features may be problematic for those with impairments. These include chats, wikis, quizzes, LMS e-mail, databases, forums, and anything where students have to fill out form-like objects.

I56 In 2011, four university experts evaluated accessibility across four LMSs: Blackboard, Desire2Learn, Moodle, and Sakai. The evaluation, although not a fully comprehensive accessibility review, looked at many commonly used features including login, navigation, tools, and customization. Each LMS was satisfactory in some features and less so in others, and they each offered different strengths and weaknesses. As explained by the study's authors, "the goal of this evaluation is not to rate or rank these LMS for accessibility but to educate the public and product development teams about how the presence or absence of certain key usability/ accessibility features can significantly impact users' experience.” The authors also link accessibility to the broader approach of universal design, focusing on usability as an essential consideration. This study offers invaluable information about each of the four LMSs (in their 2011 versions) and provides a cadre of questions to ask as you explore the accessibility and usability of features in your LMS. ${ }^{90}$

\section{Text Alternatives}

I57 Generally speaking, text should be the primary means of conveying information online because it works well with all technologies. Sometimes, of course, images and graphics are worth a thousand words. For images (photos, charts, graphics, etc.) with instructional content, the best practice is to provide alternative text that a screen reader will read. Most content editors have a space where this text belongs when you add an image that is then translated into an "alt" tag in the HTML underlying your material. ${ }^{91}$ See Figure 1.

I58 Alternative text descriptions are intended to be relatively brief, but some images — charts or graphs_-may need longer descriptions. The best way to make longer descriptions available has been hotly debated in web development circles, and resolution is still pending as markup languages, Internet browsers, and screen readers evolve.

90. Hadi Rangin et al., A Comparison of Learning Management System Accessibility, EDUCAUSE Midwest Regional Conference 2012 (Mar. 26, 2012), available at http://presentations.cita.illinois .edu/2011-03-csun-lms/; see also Rangin, supra note 88.

91. For excellent guidance on using alternative text, see Alternative Text, WeBAIM, http://webaim .org/techniques/alttext/ (last updated Aug. 29, 2013). 
Figure 1

Alternative Text for an Instructional Image

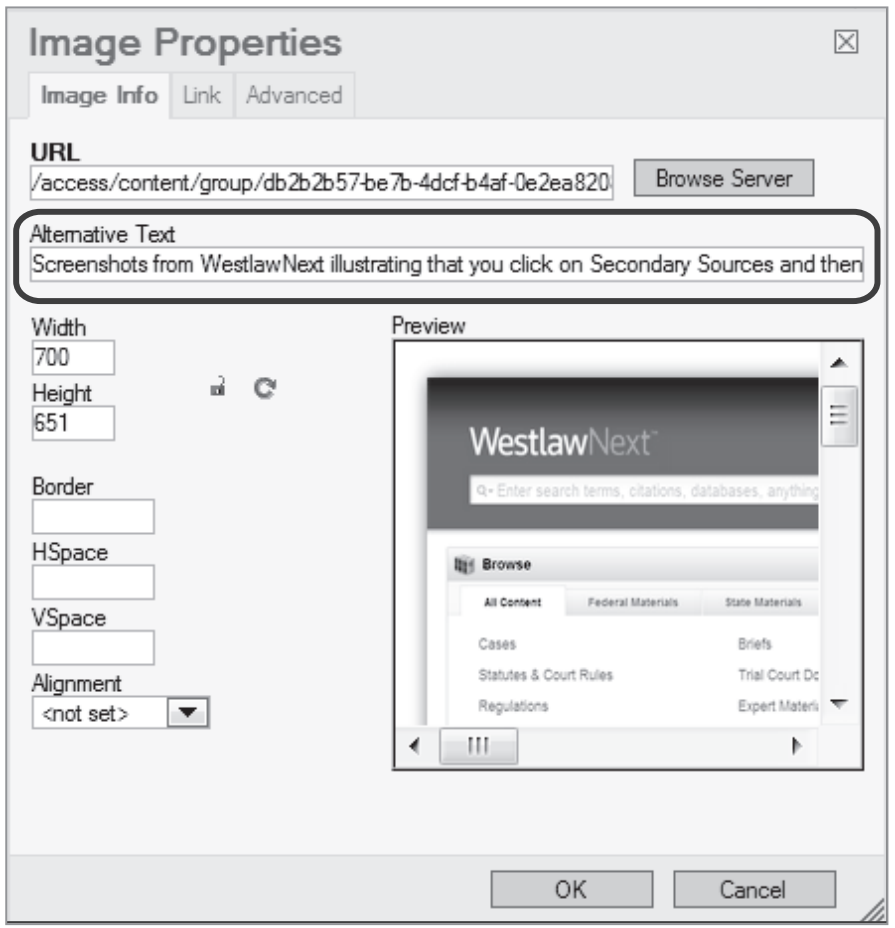

I59 If the image is for visual effect only, best practices suggest that no alternative text be used. Instead, leave the "alt" value null. ${ }^{92}$ This way, a screen reader will ignore the image completely, and the user will not waste his or her time on irrelevancies.

\60 Similarly, captioning images increases their value to every user. Most users do not have text readers that will read the alt-text fields, but a visible caption on every image can exploit a teachable moment to the fullest. Also, give images and graphics unique identifiers (e.g., Figure 1) in the captions. Use these identifiers in the text when discussing the information in the image. This is universally more effective than using location references such "above" or "below."

\section{Text-Based Menus and Other Items}

I61 Make sure all menus, form items, and similar elements are text-based rather than images or at least have alt-text that is easy to follow. Text readers cannot read images. This may be acceptable for images that are for visual effect only, but it is a showstopper if your menus, form items, links, and other essential items are images rather than text.

92. In HTML code, this would appear as: alt $=$ “"”.

93. Rangin, supra note 88. 


\section{Figure 2}

Transcript Available in Real Time with Video Using Articulate Storyline

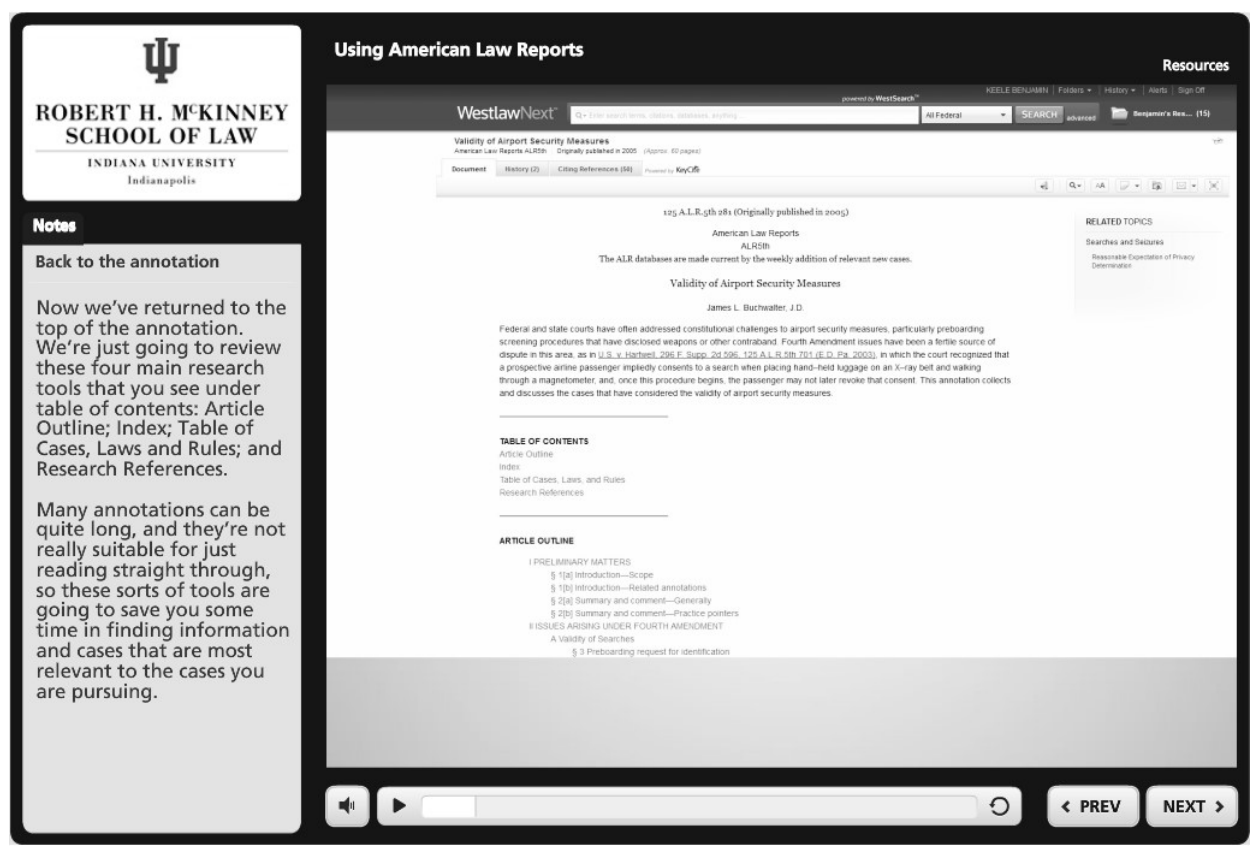

Alternatives for "Time-Based Media"

I62 The term "time-based media," which is used in accessibility standards and literature, refers to audio and video materials. These may be prerecorded or live and include both passive and interactive formats. At the most basic level, an instructor needs to provide transcripts or captioning. Other alternatives include audio descriptions of video action and sign language interpretation. ${ }^{94}$ Figure 2 shows how we have included the transcript in real time with the video, though with less precision than true captioning. We are able to do this using Articulate Storyline, an e-learning content authoring software.

\section{Alternative Navigation}

I63 Due to mobility disabilities or personal preference, students may be navigating with keyboard strokes rather than a mouse. Keystrokes for navigation are likely handled by the LMS, but it is worth double-checking. If you add your own navigation, keystroke equivalents are an important addition.

\section{Forms, Tables, PDFs}

I64 Many elements that can be used in online instruction materials are not easily made accessible. Forms and tables are prime examples. They can be used, but

94. See 1.2: Time-Based Media, Even Grounds, http://evengrounds.com/wcag-tutorial/time -based-media (last visited Feb. 18, 2015). 
attention to labeling and order is required. ${ }^{95}$ For example, each element on a form needs to have a unique label in the form's code that describes the element. A screen reader can then read this label when the focus is on the form element. ${ }^{96}$ Placing the form elements and their labels in a logical order also allows a visually impaired user to make sense of the form as read by the screen reader. Tables of data require descriptive labels as well so that the columns and rows are meaningful. ${ }^{97}$ Tables should not simply be added as images as this renders the data inaccessible to a screen reader.

I65 PDFs pose challenges because they are essentially image-based files. The International Standards Organization implemented the PDF/UA standard (ISO 14289-1:2012) in July 2012. This standard "describes the required and prohibited components and the conditions governing their inclusion in or exclusion from a PDF file in order for the file to be available to the widest possible audience, including those with disabilities." 98

$\llbracket 66$ To increase accessibility required by the PDF/UA standard, PDFs can be tagged much like HTML files. Tags indicate the logical structure and semantics of a document: sections, chapters, headings, paragraphs. Tags help identify images and other graphics and provide alternative text for these items. They build accessibility into tables and forms. Tagging also makes text and image reflow possible when a page size is changed and helps with tasks like searching, spell-checking, and exporting to other formats. ${ }^{99}$ Tagging can be done using Adobe Acrobat Pro ${ }^{100}$ or other PDF creators. Add-ins are available as well that can help tag PDFs and audit for accessibility. ${ }^{101}$ Other software such as word processors, presentation builders, and spreadsheets often allow for saving a document as a tagged PDF as well. ${ }^{102}$

I67 Dynamic content such as JavaScript-enabled controls also requires special handling. Generally, these elements will not be essential to online instruction, can be presented in more accessible formats, or will be handled by the LMS, but guidance for making them accessible is available if needed. ${ }^{103}$

95. Chisholm \& MaY, supra note 88, at 51-75 (discussing tables and forms).

96. SYDIK, supra note 8 , at 130-31.

97. Id. at 106-16. In the Sakai-based LMS I have been using, you can add a table to a lesson page, and you can add labels (headers) to both rows and columns, a title (caption), and a summary. More advanced labeling would need to be coded by hand.

98. PDF Techniques for WCAG 2.0, W3C (2012), http://www.w3.org/TR/WCAG20-TECHS/pdf .html.

99. Id.

100. See About Tags, Accessibility, Reading Order, and Reflow, AdobE Acrobat X Pro, http://help.adobe.com/en_US/acrobat/X/pro/using/WS58a04a822e3e50102bd615109794195ff-7d2d .w.html (last visited Feb. 18, 2015).

101. Examples of plug-ins include CommonLook PDF (plug-in for Acrobat) and CommonLook Office (plug-in for Office). See Products and Services, CommonLook, http://www .commonlook.com/commonlook-software-services-and-training-for-accessible-pdf (last visited Feb. 18, 2015). In addition, PAC: PDF Accessibility Checker is a freeware auditing program that tests accessibility of PDF files. See Free PDF Accessibility Checker, ACCESS FOR ALL, http://www.access-for-all.ch /en/pdf-lab/pdf-accessibility-checker-pac.html (last visited Feb. 18, 2015).

102. Creating Accessible PDFs, OfFICE, http://office.microsoft.com/en-us/word-help/create -accessible-pdfs-HA102478227.aspx (last visited Feb. 18, 2015).

103. See Roger Johannsson, Accessibility Does Not Prevent You from Using JavaScript or Flash, 456 BEREA STREET, http://www.456bereastreet.com/archive/201005/accessibility_does_not _prevent_you_from_using_javascript_or_flash/ (last visited Feb. 18, 2015); Rangin, supra note 88 (providing instruction on accessibility for these and other elements). 


\section{Flexible Use}

I68 To be flexible, online materials must be designed so that students can access them in multiple ways. This can mean anything from ensuring that users can control the display of colors and fonts to designing so that students can use the materials on tablets and smartphones as well as laptops and desktops.

\section{Separation Between Content and Presentation}

I69 As long as humans have been sharing information, we have been distinguishing between content and presentation. The cave paintings at Lascaux are one choice as to presentation of the day's adventure while a tale of the hunt shared around a fire is another. In the online realm, the division between content and presentation is especially powerful because it allows the user to control presentation if so desired. Using proper techniques, online instructors can create content along with default presentation choices and yet still allow users with unique needs to override the presentation defaults without affecting the content.

I70 The first step is to use "styles" rather than hard-coded text formatting to create headings and other structural cues within your content. An instructor uses text formatting when she creates a heading by selecting the text and then using the formatting options to change to a new font, increase the font size, and make the text bold. Unfortunately, screen readers do not pick up the logical difference between this formatted text and the text of the subsequent paragraph or any other text. The better practice to select the text and apply a style such as "Heading 1" or "Heading 2." This adds an unseen tag to the text. This tag tells a browser to use display setting for Heading 1 on that bit of text, and a screen reader will use the tag to communicate the structure of the material. Most text editors offer tags in a menu of choices: Title, Subtitle, Heading 1, Heading 2, Heading 3, Paragraph, and so on. ${ }^{104}$

I71 Text formatting such as bold or italic should be used when only the appearance is meaningful, not the organizational structure. Examples include italicized foreign words or titles in a citation or emphasis of certain phrases.

I72 Browsers have certain default settings that determine how the tagged content appears. Disabled students can adjust these settings to suit their own needs. The appearance can also be changed and controlled with separate style sheets created in a coding language such as Cascading Style Sheets (CSS). ${ }^{105}$ See Figure 3. Style sheets make it possible for an instructor to create a certain consistent appearance for most students while still allowing disabled students the freedom to create their own appearance. Styles are also a boon for an instructor since they allow global changes in appearance to be made easily with a few keystrokes.

104. The Sakai-based LMS in which I have been working for the past three years is confusing because it has a text editor that offers two menus, one labeled Styles and one labeled Format. The Styles menu offers tags that are more appearance-based-Sample Text, Đeleted Text, Variable — while the Format menu offers the structural tags such as Heading 1. Regardless of what they are called, the structural tags are the vital ones for keeping presentation and content separate.

105. For an introduction to CSS, see Jon Duckett, HTML and CSS: Design and Build WebSITES (2011). 
Figure 3

A Brief CSS File with Matching Output

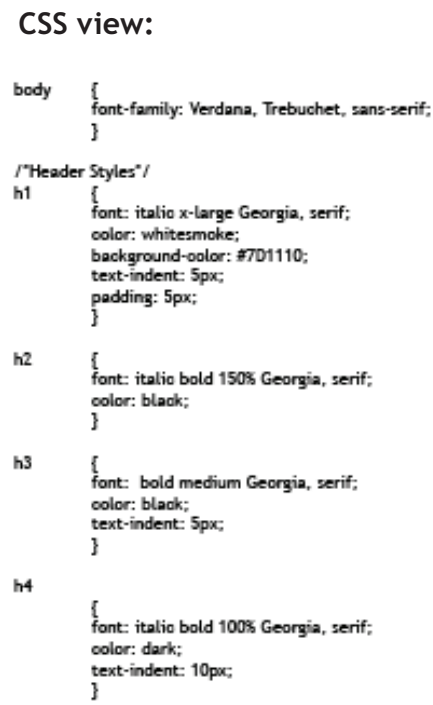

Onscreen view:

This is body text. The CSS file names a font family for normal text in the body, but otherwise leaves everything to default. Of course, an individual can override the CSS file if necessary.

\section{Heading 1 will look like this.}

\section{This is Heading 2,}

\author{
and Heading 3,
}

and last but not least, Heading 4 .

\section{Multiple Formats}

I73 The principle of flexibility also requires that online materials keep up with technological changes. The past few years have seen a remarkable increase in the use of mobile devices among students. Computer labs where all the software is tightly controlled by IT are dwindling and being replaced by a proliferation of laptops, tablets, and smartphones. Online instructors need to ensure that their materials can be used on all these devices. As an example, a screencast for a legal research class may need to be published as a Flash file, an MP4, and possibly others as well.

\section{Simplicity}

I74 Google revolutionized search interfaces when it reduced the concept of an Internet search screen to a white screen adorned with nothing but an attractive logo and a search bar. The simplicity was breathtaking-so easy, so intuitive, so consistent. The only thing that changes is the Google Doodle. With the underlying simplicity of the page intact, users can enjoy the quirky surprise of the Google Doodle without losing their bearings. Simplicity is key in universal design because it always leads to greater accessibility while leaving opportunities for sensory appeal.

\section{Consistent Design, Structure, Navigation}

I75 When designing an online course or online materials, keep both the structure and the appearance clean, logical, and consistent. The structure of the information should be so clear that students can focus on the content without having to find their way through a mass of information. 
I76 Likewise, navigation should be explicit, straightforward, and logical. Navigation bars or panels should be the same on all pages and should always include a link to the home page. Most navigation options exist in the LMS rather than in the materials themselves. This means that an instructor may have choices about which navigation options appear in the navigation bars or panels but does not have to worry about the coding. However, if coding is necessary, best practices dictate that navigation menus be built from unordered lists and be introduced by a heading. This makes it possible for screen readers to identify and read the navigation links properly. ${ }^{106}$ Also, if navigation links use images such as buttons rather than plain text, be sure to include alternative text.

I77 Finally, in addition to structure and navigation, the design of materials should be consistent throughout. Typeface, font size, use of color-all these design choices need to carry through all materials. This can be difficult, especially as materials get used from one semester to the next and as new material is created. Style sheets that apply styles across multiple pages can help alleviate this challenge. So too can old-fashioned checklists, especially for embedded material such as videos, graphics, or screenshots.

\section{Clear, Specific Instructions}

I78 Like consistent design, providing clear, well-formatted, and easy-to-find instructions such as syllabi, assignments, and expectations benefits everyone. Figure 4 shows the instructions that accompany the links provided for every assignment in an online class. The paragraph explains what each link is for and suggests how to use the materials at each link. The links themselves repeat what they link to and clarify which one will take students to a PDF that they can print and which one will let them submit answers.

\section{Figure 4}

\section{Links with Instructive Text}

\section{Links}

The first link below will take you directly to Assignment 2 online. The second link provides a print version. You may find it helpful to print out the assignment and review it prior to working through the instructional materials. Students have found it useful to work on the print version before entering the answers into the online assignment for submission.

Assignment 2 -- Online (submit answers here)

Assignment 2 -- Print (PDF) 
I79 It may seem like overkill to include an indication that the print version is a PDF rather than a Word document or some other text document. In fact, this kind of forewarning helps those students using screen readers know what to expect when they click. Screen readers are sensitive to file formats (as noted above, PDFs can cause problems for screen readers if not properly tagged), and best practices indicate that information about format is best given before the link is clicked.

\section{No Distractions}

I80 We are all easily distracted in the online environment, but some impairments make distractions even more problematic. Best practices in accessibility prescribe reducing distractions as much as possible: set apart links to further information, do not include anything flashing or flickering, reduce unnecessary clipart, ensure that time-based media (video and audio) are not set to start automatically. To achieve this last item, the presentation videos in our online class now include an initial screen with a Play button on it (no Play button is available on the player itself). This Play button is a hotspot that links to the next page where the presentation actually begins. Nothing happens until the Play button is clicked.

\section{Perceptibility}

I81 The principle of perceptibility goes hand in hand with that of simplicity. These two form the core of the universalness in universal design for online learning because they so clearly benefit everyone.

\section{Readable Language}

I82 Much has been written about "writing to be understood," especially in the legal field. ${ }^{107}$ In an online environment where it can be is easy to lose track of structure and location, readability is especially important. Avoid or explain lingo, keep sentences relatively short, and use plenty of hierarchical indicators.

I83 For large amounts of online text, sans serif fonts are preferred, and the default size (generally 16 pt in most web browsers) should be used. Captions and labels can be smaller; titles and headings can be larger. Titles and headings can also make use of serif fonts, though script or fanciful fonts are best avoided.

I84 It is also recommended that lines of text be roughly 50 to 75 characters long. ${ }^{108}$ A typical line of text in Law Library Journal runs between 80 and 85 characters, including spaces. Estimates on the perfect range vary somewhat, but it is safest not to exceed 100 characters per line for online sustained reading material. ${ }^{109}$

107. For a recent example of the "plain language" movement, see JOSEPH KimBLE, WrITING For Dollars, Writing to Please (2012).

108. See Robert Bringhurst, The Elements of Typographic Style (2004); see also Christian Holst, Readability: The Optimal Line Length, BAYMARD INST. (Nov. 1, 2010), http://baymard.com /blog/line-length-readability.

109. See M. Jackson Wilkinson, The Line Length Misconception, VIGET (May 7, 2009), http://viget .com/inspire/the-line-length-misconception (citing A. Dawn Shaikh, The Effects of Line Length on Reading Online News, 7 UsabiLITY NEWs, July 2005, available at http://psychology.wichita.edu/surl /usabilitynews/72/LineLength.asp). 


\section{Color}

I85 Information on color theory abounds, and color can be used to create many different moods and effects. ${ }^{110}$ For purposes of universal design and usability in online instructional materials, there are three essentials:

1. Preferred colors are those that do not pose problems to the colorblind. ${ }^{111}$ The majority of colorblind people struggle to distinguish between red and green. Other colors can pose problems as well, but red and green are the most common.

2. Color should not be the only way the information is conveyed. Pair color with text or pattern to ensure the information is communicated.

3. Color should not be distracting. To achieve this, use a restrained palette and use the colors in that palette consistently-in the same or similar ways across all materials. For example, use pale yellow behind all callouts or use a dark blue shadow frame behind all images.

\section{Layout and Format}

I86 Tastes and trends in layout for online materials change, but there are graphic design rules that withstand the test of time because they are about more than appearance; they are about transmitting information. ${ }^{12}$ Graphic design considerations can fill books, but the most important ones, in brief, include the following:

I87 Contrast communicates difference. It helps our eyes and brains quickly distinguish between elements. One aspect of contrast is the need for adequate contrast between background and text (or other foreground material). Regardless of the reader's visual acuity, dark text on a white or off-white background is best for sustained reading. Light background colors work well for smaller amounts of emphasized text, perhaps a callout or an important sentence. Dark backgrounds with white or very light text should be limited to titles, upper-level headings, labels, and the like.

I88 A title with a dark background and white text leads to another use of contrast: creating distinctions between objects in the foreground. The title is distinct from the body of the text, so it stands out and communicates organizational structure. The key to this use of contrast is making the elements different enough that the meaning is evident immediately. Fine distinctions are not effective. If you want

110. See, e.g., Josef Albers, Interaction of Color (50th ann. ed. 2013). For a more introductory text, see Patti Mollica, Color Theory (2013) or Linda Holtzchue, Understanding Color: AN INTRODUCTION FOR DESIGNERS (2011).

111. Color choices can be checked-for appropriate contrast as well as perceptibility by the colorblind-using color accessibility tools. Many are included on the W3C WAI's list at http://www .w3.org/WAI/ER/tools/.

112. There are many books on the design aspect of websites and online content. These include, but are in no way limited to, Jason Beaird, The Principles of Beautiful Web Design: A Practical Guide to a Useful, Beautiful Web (2007); John Cato, User-Centered Web Design (2001); Alexander Dawson, Distinctive Design (2011); Brian Miller, Above the Fold: Understanding the Principles of Successful Web Site Design (2011); Robin Williams, The Non-Designer's Design Book (2d ed. 2004); Robin Williams \& John Tollett, The Non-Designer's Web Book (3d ed. 2006). 
to make a certain element bigger and bolder, make it considerably bigger and bolder rather than just slightly so.

I89 Hearkening back to the scenario of the law professor's class blog, contrast was an issue with the blog as originally created. The professor had chosen a template that used dark gray text on a medium to light gray background. The result was very muted and elegant but difficult for sustained reading or for anyone with vision impairments. Fortunately, this was easy to change in Blogger, and he now uses a very dark gray text on a white background.

I90 Proximity builds on contrast by using filled spaces and negative spaces to communicate meaning. Proximity is the idea that things near one another are related while things that are separated from one another are less or not related. An easy example is an address, a phone number, and an e-mail. Typically, these items are together on a page or a business card because they are all the same kind of information. In online instructional materials, a bulleted list of topics covered on the page might be listed at the top followed by white space before the actual content begins, creating a group of related items separated from the rest of the information. Proximity is also helpful in clarifying which lessons go with which topic, as in Figure 5.

I91 Alignment both creates balance and provides our eyes with signals as to the structure and flow of elements on a page. This does not mean that everything on the page must adhere to the left side. Balance is sometimes created through a combination of aligning the edges of some elements while offsetting another element. The key is that all elements are visually tied to other elements on the page. ${ }^{113}$

$\mathbb{1 9 2}$ For many people, the default is to center an element on the page. This is effective when there is very little on the page and what is there makes a powerful statement or visual effect. Google's search page is a good example. Center alignments are weak for text and multiple elements. There are no hard edges for our eyes to follow, and the text is difficult to read.

193 The tried-and-true left alignment may seem boring, but it gives our eye a strong line indicating the beginning of the text, and it is easy to scan. Left alignment should always be used for sustained reading text, at least in cultures that read left to right. Right alignment is also strong, but because we read left to right, it is not effective for anything other than short bursts of text. Right alignment makes text stand out and seem unique. It is effective for callouts and quotes. ${ }^{114}$

I94 Repetition of design features helps users know what to expect. Many different kinds of repetition help us navigate and understand online instructional materials. For example, place the same Next, Back, and Home buttons on every page. Use the same typeface and size for every page title. Place the same kind of frame around every image. Another layer of repetition is to use an icon that means "This is important!" and place this icon next to every key idea.

I95 Repetition of purely decorative features can create a sense of unity and flow as well. Websites will often repeat a color scheme or logo on every page of their sites

113. See Williams, supra note 112 , at 31.

114. See Joshua Johnson, Design101: Utilizing Strong Alignments, Design Shack (Aug. 27, 2010), http://designshack.net/articles/graphics/design101-utilizing-strong-alignments/. 


\section{Figure 5}

Using Proximity to Clearly List Topics and Lessons
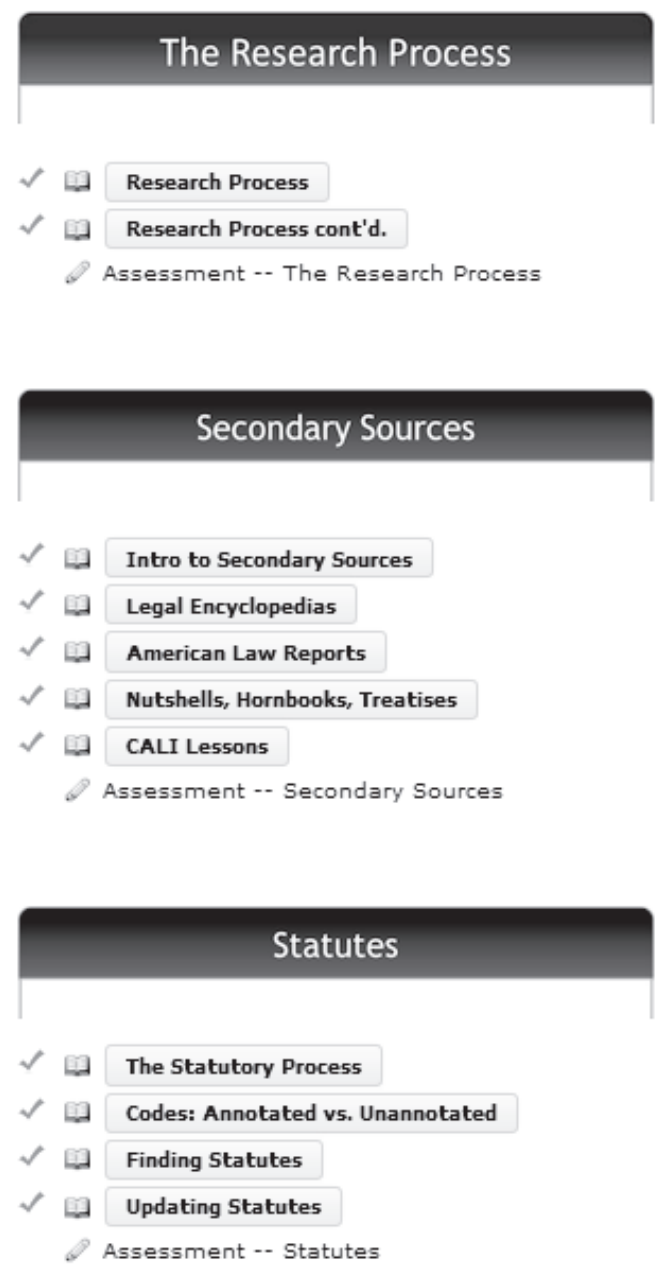

so that users know they are still within that particular website. Similarly, we chose to use crimson backgrounds for every title and top-level heading in our instructional materials. Not only does this allow students to identify the structure of the page quickly, but it also creates a familiar "look and feel" that lets students know they are still within the lesson. ${ }^{115}$

\section{Tolerance for Error}

I96 The frustration felt when you hit the wrong button or press the wrong key and disaster strikes is surely universal, as is the relief when those mistakes can be undone. People with impairments may be more likely to experience unintended 
interactions with online materials. Good design allows for unintended actions and reduces the consequences of mistakes. The following practices help achieve this:

- Ensure that the navigation allows for both forward and backward movement.

- Create large target areas for any necessary clicking such as buttons, links, and menus.

- Use simple menus with little to no nesting.

- Create or enable verification for risky actions.

- Always provide confirmation of submissions.

\section{Low Physical Demands}

\97 Although it may seem that the online realm has minimal physical demands by its very nature, this principle prompts consideration of fine motor and cognitive stamina and fatigue. Reading online or watching instructional videos and recorded lectures is fatiguing, even after ten or fifteen minutes. Clicking and typing can be tiring as well, especially if a student has motor impairments. Generally, materials need to be divided into manageable portions so that a student can regulate his or her own pace. Structure the materials along natural breaking points to facilitate pacing.

\section{Appropriate Space and Size for Use}

I98 The final principle of universal design may also seem less relevant in the online realm than in the material realm, but it serves as the logical conclusion of the work done under the other six principles and can act as a checkpoint. Have we allowed for flexible approaches? Have we made text, navigation controls, and target areas large enough? Is information spaced and paced appropriately? Does our layout allow for intuitive use and easy reading? Have we created consistency and predictability? Have we left room for the user to control the digital environment? The end result is online instructional materials that are appropriate for use by everyone.

\section{Conclusion}

199 A sea change is about to occur in legal education as mainstream, ABAaccredited schools implement more online classes. Among the many challenges that will follow is the need to ensure that these online classes are accessible to students with visual, hearing, or mobility impairments.

I100 The law does not yet explicitly require online classes to meet standards of universal access, but this may soon change. ${ }^{116}$ Furthermore, the CVAA signals that

116. See supra II 27; Golden, supra note 32, at 411 (concluding that "where the Internet and disability law's applicability to institutions of higher education intersect, the result should be clear: colleges and universities have an undeniable legal obligation to make their programs and services accessible to students with disabilities."). 
the law is reaching further to ensure equitable access to online materials. The writing is on the wall.

I101 Many law librarians and professors do not have the knowledge needed to ensure that their online classes are accessible. Even when they do have the knowledge, it takes time to implement everything that can be done. Although some instructors may receive technical support that makes the process easier, many are left to their own devices. Either way, a working knowledge of the considerations that must go into ensuring accessibility is beneficial. Law librarians and professors with the necessary knowledge are likely to make better decisions in designing and creating online materials.

I102 Standards exist for such materials, but they can be difficult to understand and apply. When we use principles of universal design to guide the creation of online materials that everyone can use, the end result is a more holistic approach that gives shape and meaning to the technical standards. Not only does the purpose of the standards come through more clearly, but the standards are also enriched with a more design-centered focus that seeks effectiveness in form as well as function.

I103 Perhaps the most meaningful aspect of universal design, both rhetorically and actually, is that people with "impairments" are not singled out for accommodation. Instead, we are all end users, regardless of abilities, and the design of our environments benefits us all. Disability begins to disappear. ${ }^{117}$ By viewing the laws and technical standards of accessibility through this lens, we may, in the end, be better able to achieve not only the pedagogy but also the equality of information that is part of librarianship's ethos. 